\title{
$\operatorname{CONF-970583--1}$
}

\section{APPLICATION OF DIGITAL IMAGE ANALYSIS FOR SIZE DISTRIBUTION MEASUREMENTS OF MICROBUBBLES}

\author{
Susan E. Burns, Sotira Yiacoumi, and J. David Frost \\ School of Civil and Environmental Engineering \\ Georgia Institute of Technology \\ Atlanta, Georgia 30332-0512
}

and

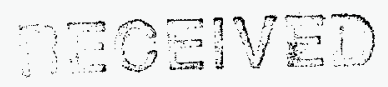

Costas Tsouris

$F=1210 \%$

Chemical Technology Division

Oak Ridge National Laboratory*

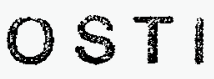

P. O. Box 2008

Oak Ridge, Tennessee 37831-6226

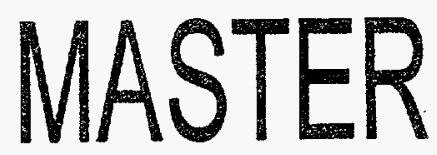

Submitted for publication in proceedings:

IMAGING TECHNOLOGIES: Techniques and Civil Engineering Applications

Engineering Foundation

Davos, Switzerland

May 25-30, 1997

The submitted manuscript has been authored

by a contractor of the U.S. Government

under contract No. DE-ACO5-960R22464.

Accordingly, the U.S. Government retains a

nonexclusive, royalty-free license to

publish or reproduce the published form

of this contribution, or allow others to

do so, for U.S. Government purposes.

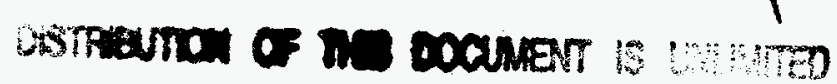

*Oak Ridge National Laboratory, managed by Lockheed Martin Energy Research Corp. for the U.S. Department of Energy under contract number DE-AC05-96OR22464. 


\section{DISCLAIMER}

This report was prepared as an account of work sponsored by an agency of the United States Government. Neither the United States Government nor any agency thereof, nor any of their employees, make any warranty, express or implied, or assumes any legal liabiity or responsibility for the accuracy, completeness, or usefulness of any information, apparatus, product, or process disclosed, or represents that its use would not infringe privately owned rights. Reference herein to any specific commercial product, process, or service by trade name, trademark, manufacturer, or otherwise does not necessarily constitute or imply its endorsement, recommendation, or favoring by the United States Government or any agency thereof. The views and opinions of authors expressed herein do not necessar. ily state or reflect those of the United States Government or any agency thereof. 


\section{DISCLAMMER}

Portions of this document may be illegible in electronic image products. Images are produced from the best available original document. 


\title{
Application of Digital Image Analysis for Size Distribution Measurements of Microbubbles
}

\author{
Susan E. Burns ${ }^{1}$, Sotira Yiacoumi ${ }^{1}$, David Frost ${ }^{1}$, and Costas Tsouris ${ }^{2}$
}

\begin{abstract}
This work employs digital image analysis to measure the size distribution of microbubbles generated by the process of electroflotation for use in solid/liquid separation processes. Microbubbles are used for separations in the mineral processing industry and also in the treatment of potable water and wastewater. As the bubbles move upward in a sotid/liquid column due to buoyancy, particles collide with and attach to the bubbles and are carried to the surface of the column where they are removed by skimming. The removal efficiency of solids is strongly affected by the size of the bubbles. In general, higher separation is achieved by a smaller bubble size. The primary focus of this study was to characterize the size and size distribution of bubbles generated in electroflotation using image analysis. The study found that bubble diameter increased slightly as the current density applied to the system was increased. Additionally, electroflotation produces a uniform bubble size with narrow distribution which optimizes the removal of fine particles from solution.
\end{abstract}

\section{Introduction}

Many environmental and industrial treatment processes rely on the separation of solid particles from liquid solutions. Traditionally, solid particles are removed by sedimentation; however, sedimentation does not work well for low density particles like clay minerals, spores, and coagulated fulvic acids (Edzwald et al., 1992; Malley and Edzwald, 1991; Letterman, 1987). As a result, a method known as flotation, which floats rather than sediments low density particles, is being used more commonly. In flotation, small gas bubbles are generated at the bottom of the water column to be treated. The microbubbles then rise to the surface of the liquid through buoyancy. As the bubbles rise, they collide with and adsorb to particles in the

${ }^{1}$ Graduate Research Assistant, Assistant Professor, and Associate Professor, respectively, Georgia Institute of Technology, School of Civil and Environmental Engineering, Atlanta, GA 30332-0355

${ }^{2}$ Chemical Technology Division, Oak Ridge National Laboratory, P.O. Box 2008, Oak Ridge, TN $37831-6226$ 
solution; consequently, the low density solids are floated to the top of the column for removal by skimming. The process of flotation is known as dissolved air flotation if the microbubbles are produced by pressurizing air into water, as dispersed air flotation if the bubbles are produced by forcing gas through a sparger, and as electroflotation if the bubbles are produced through the electrolysis of water. This study will focus on bubbles generated by electroflotation.

Electroflotation has been used by the mineral processing industry for the recovery of mineral particles (Ketkar et al., 1991), and in environmental and industrial processes for the separation of oil from oil/water emulsions (Hosny, 1992; Balmer and Foulds, 1986), and for the removal of coagulated heavy metals from solution (Srinivasan and Subbaiyan, 1989; Ramadorai and Hanten, 1986). In all of these applications, the removal efficiency is strongly affected by the size of the generated bubbles. Smaller bubbles have a longer residence time in the system, have a larger surface area, and are more likely to adhere to solids after a collision (de Rijk et al, 1994). Consequently, the treatment process is optimized by generating the smallest diameter bubbles possible.

This paper examines the effect of the process variables of voltage, current, and ionic strength on the size of the bubbles generated during electroflotation. Bubble images were recorded with a long-distance, high-magnification microscope, and were printed and imported into a digital image analysis for measurement of equivalent bubble diameter. The average equivalent circular diameter for was calculated for each experimental condition; additionally, the volume distribution of the bubbles was calculated for each experiment.

\section{Experimental}

The rectangular test cell used in the experiments of this study was made of Plexiglas with dimensions of $58.4 \mathrm{~cm}$ by $7.6 \mathrm{~cm}$ by $2.5 \mathrm{~cm}$. Inflow and outflow ports were drilled in the top and bottom of the cell and it was mounted vertically in order to allow gas flow out the top. After the cell was filled with the test solution, a soap-film flow meter was attached to one outflow port to measure gas flow rate and the remaining outflow ports were sealed. The electrodes used in the experiments were polished graphite electrodes $(7.6 \mathrm{~cm}$ by $2.5 \mathrm{~cm}$ by $1.3 \mathrm{~cm}$ ) and were mounted at the bottom of the cell with a separation of $13 \mathrm{~cm}$. Electrical leads were attached to the electrodes using conductive epoxy, and then connected to an external power supply.

Twenty eight experiments were performed using aqueous solutions of deionized water mixed with $\mathrm{Na}_{2} \mathrm{SO}_{4}$ at ionic strengths of $0.1,0.01$, and $0.001 \mathrm{M}$. In the experiments, the voltage was varied from 15 to $86 \mathrm{~V}$ and the current was varied from 11 to $288 \mathrm{~mA}$. Current was applied to the system using a high-voltage, highcurrent power supply and the generated bubbles were videotaped using a long- 
distance microscope with a magnification of approximately 230 times attached to a video camera, monitor, and VCR. The calibration factor was a wire of known diameter. The experiments performed at $0.001 \mathrm{M}$ did not produce a significant gas flow rate; consequently, only the results for the experiments performed at 0.1 and $0.01 \mathrm{M}$ are reported in this paper.

The gas bubbles produced in electroflotation form through the electrolysis of water by the following redox reactions:

$$
\begin{array}{ll}
\mathrm{H}_{2} \mathrm{O} \rightarrow 2 \mathrm{H}^{+}+1 / 2 \mathrm{O}_{2}(\mathrm{~g})+2 \mathrm{e}^{-} & \text {Anode }(+) \\
2 \mathrm{H}_{2} \mathrm{O}+2 \mathrm{e}^{-} \rightarrow 2 \mathrm{OH}^{-}+\mathrm{H}_{2}(\mathrm{~g}) & \text { Cathode(-) }
\end{array}
$$

The oxygen and hydrogen gas dissolve into the liquid surrounding the electrodes; when the liquid becomes supersaturated with gas, bubbles begin to form on the electrode surface (Verhaart et al., 1980). The camera was focused on the bottom electrode in the test cell and two experiments were performed at each power level. In the first experiment, the bottom electrode was the anode, and in the second experiment the electrical leads were reversed making the bottom electrode the cathode. This configuration was used because it prevented the mixing of oxygen and hydrogen bubbles during videotaping. A light source was set up behind the cell to produce contrast between the bubbles and the solution in the recorded images.

\section{Image Processing and Analysis}

After the experiments were completed, the images were printed to hard copy using a video copy processor and imported into a Quantimet Q570 Digital Image Processor. The printed images were gray-scale pictures of dark bubbles on a light background because the light source behind the cell was blocked by the bubbles but passed through the aqueous solution. After the images were acquired by the image processor, they were converted from gray-scale into digital images and a minimal amount of image processing was performed. In some instances, background noise occurred on the images and was erased. Additionally, sometimes two bubbles touched each other on the images. In this case, the bubbles were either separated and analyzed individually, or were eliminated from the image. No other image processing was performed on the bubble pictures. Because not all of the bubbles were circular in cross-section, the image analyzer measured the area of each bubble and converted that to an equivalent circular diameter for the output.

A statically valid sample size was chosen for analysis by first determining the

error in the measurement. Measurements of one experiment were performed twice and the difference was $1.9 \mu \mathrm{m}$ between the average diameters measured. Assuming a normal distribution, and choosing a $95 \%$ confidence interval, the sample size was calculated by the following (Hines and Montgomery, 1990): 


$$
n=\left(\frac{Z_{\alpha i 2} \sigma}{E}\right)^{2}
$$

where $n=$ sample size, $Z_{\alpha / 2}=$ confidence interval, $\sigma=$ standard deviation, and $E=$ error.

$\underline{\text { Resuits }}$

Figure 1 shows a plot of the equivalent circular diameter of oxygen bubbles as a function of current density. The figure shows a trend of slightly increasing bubble diameter with increasing current density applied to the system. This is consistent with other electroflotation results using metallic electrodes (Brandon and Kelsall, 1985; Janssen and Hoogland, 1973; Landolt et al., 1970). The formation of bubbles in electroflotation is an inhomogeneous, or surface controlled, process rather than a homogeneous process where the bubbles form out of solution without the presence of a surface. Previous research has found that bubbles will form at the location of scratches and pits on the electrode surface (Janssen and Hoogland, 1973; Glas and Westwater, 1964) which illustrates the importance of the surface characteristics of the electrodes. In this study, the electrodes were not polished between successive experiments which most likely explains the scatter seen in the average bubble diameter measurements because the application of current will affect the surface characteristics of the electrode. Average oxygen and hydrogen bubble diameters measured in the experiments ranged from 17.1 to $37.9 \mu \mathrm{m}$, which is consistent with the size of bubbles produced on stainless steel and platinum electrodes (Ketkar et al., 1991).

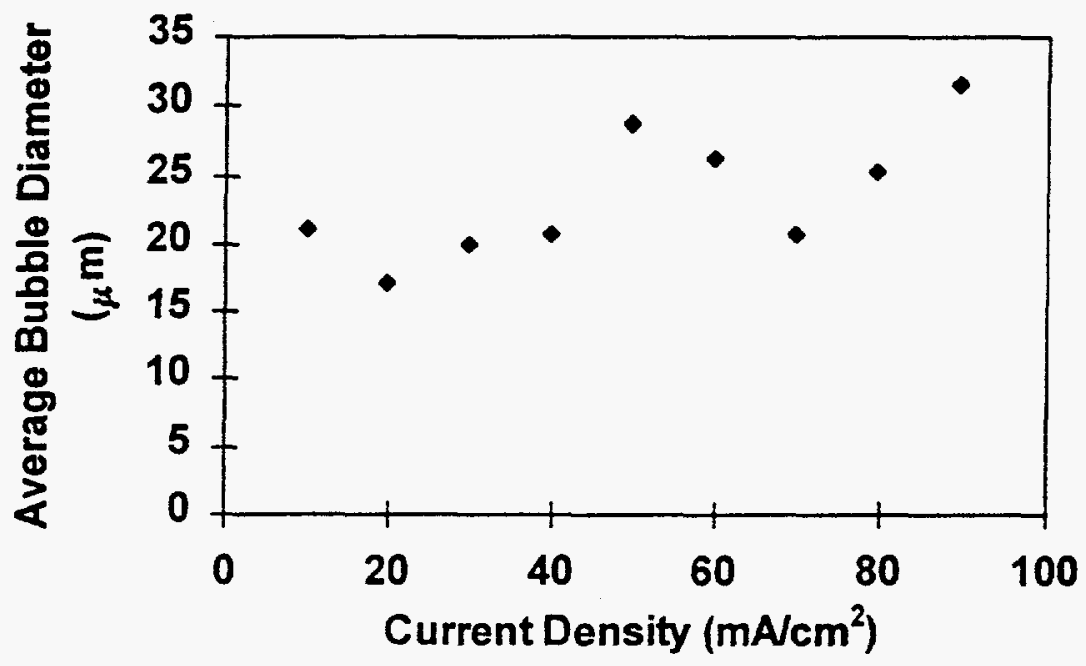

Figure 1. Oxygen bubble diameter as a function of current density: $I=0.1 \mathrm{M}$. 
No clear trends in bubble size were seen as a function of voltage or as a function of ionic strength; however, volume of gas generated was a strong function of both power input to the system and of ionic strength of the surrounding medium. As would be expected, the generation of hydrogen and oxygen gas increased as both the power input to the system was increased and as the ionic strength of the aqueous medium was increased.

The volume distribution of the generated bubbles was also plotted for comparison between the experimental conditions. Figures 2 and 3 show the volume

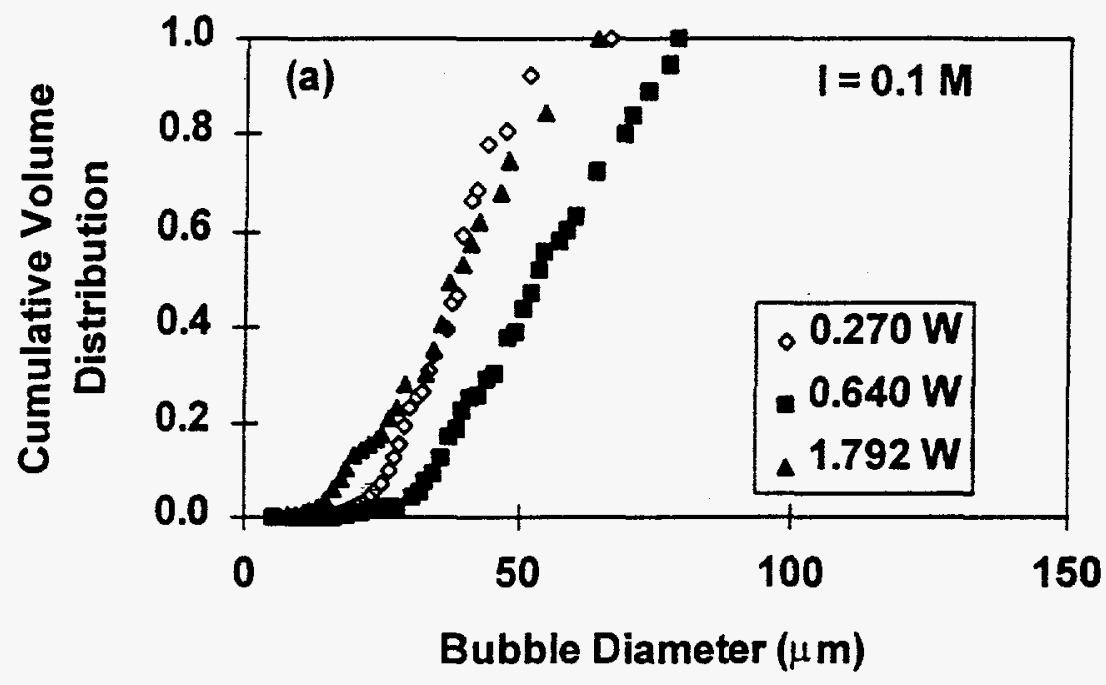

Figure 2(a). Cumulative volume distribution for hydrogen bubbles: $\mathrm{I}=0.1 \mathrm{M}$.

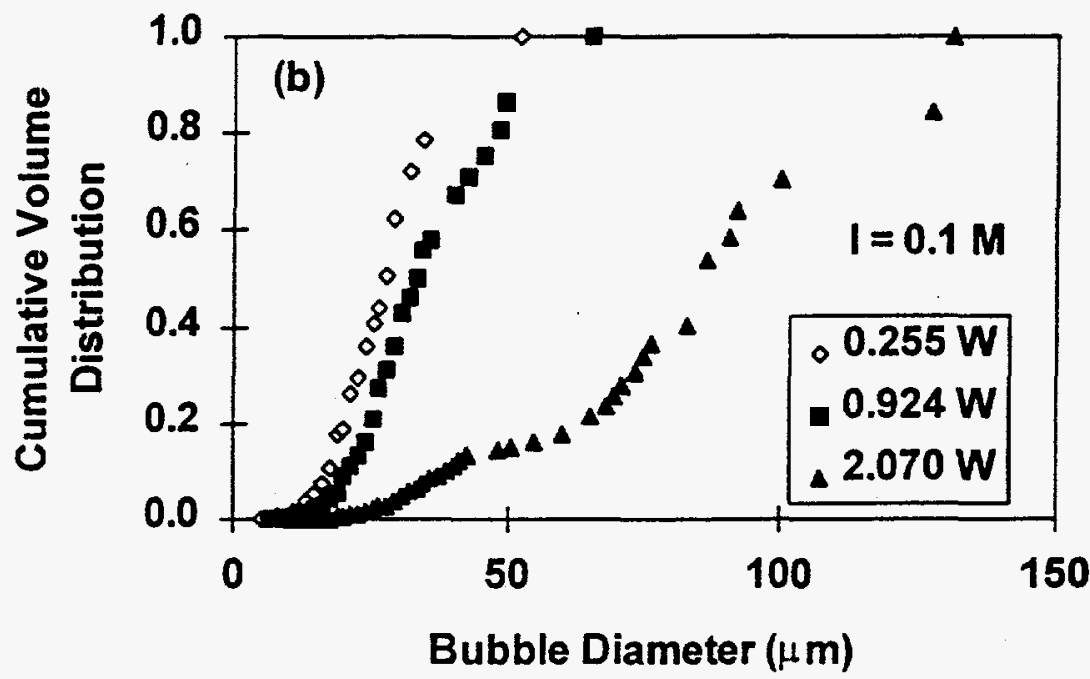

Figure 2(b). Cumulative volume distribution for oxygen bubbles: $\mathrm{I}=0.1 \mathrm{M}$. 
distribution of both the oxygen and hydrogen bubbles produced at ionic strengths of 0.1 and $0.01 \mathrm{M}$ and at power levels ranging from 0.255 to $2.070 \mathrm{~W}$. The distribution plots show that electroflotation produces bubbles with fairly uniform diameters. The most common range in bubble diameters is approximately $60 \mu \mathrm{m}$, which is a rather narrow distribution for flotation methods. Additionally, the majority of the bubbles produced have diameters smaller than $50 \mu \mathrm{m}$ which increases the removal efficiency of fine particles from the solution. However, as was seen with average bubble diameter, no distinct trends in the distribution are seen as functions of either power or ionic strength.

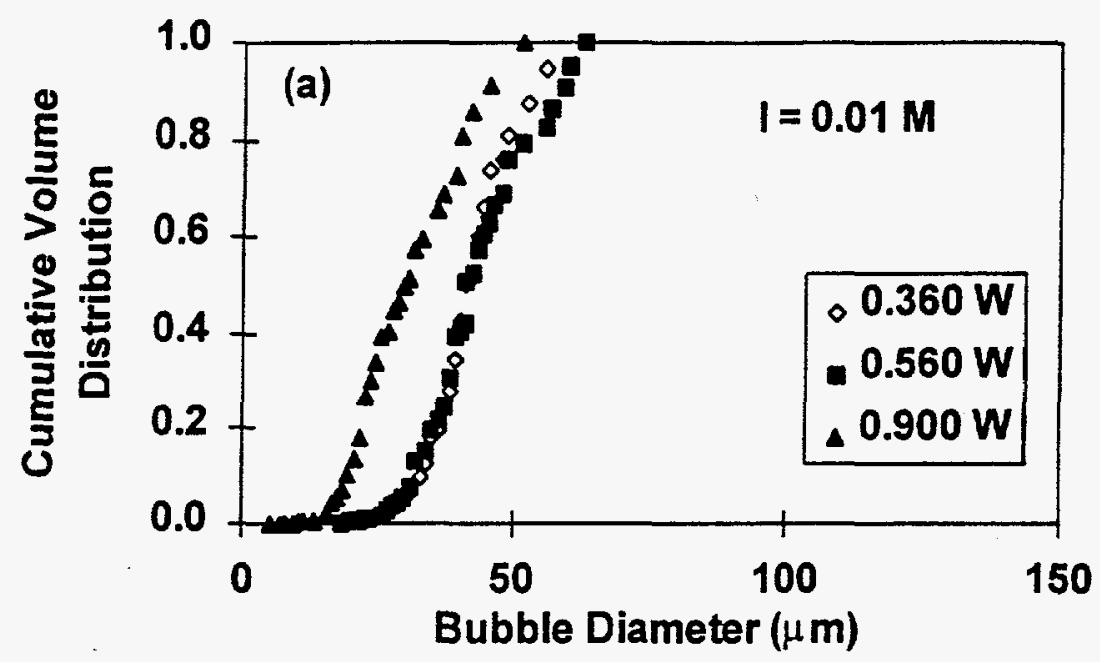

Figure 3(a). Cumulative volume distribution for hydrogen bubbles: $\mathrm{I}=0.01 \mathrm{M}$.

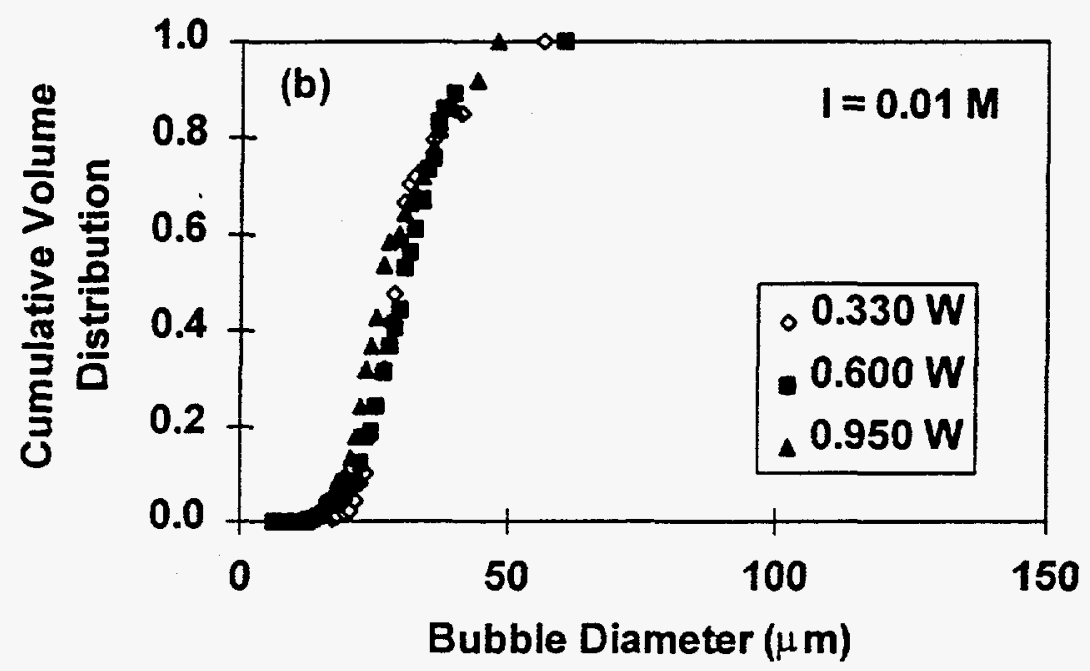

Figure 3(b). Cumulative volume distribution for oxygen bubbles: $\mathrm{I}=0.01 \mathrm{M}$. 


\section{Conclusions}

Digital image analysis provided an efficient method for measuring the average equivalent diameter of microbubbles produced by electroflotation. The use of automated measuring processes allowed for the rapid determination of bubble size and eliminated the measurement errors which can occur in manual measurements. Because the measurement process is faster using an image analyzer than manual measurements, a larger sample space can be used and/or more experiments can be performed allowing for more complete data sets.

In these experiments, the average bubble diameter increased as the current density applied to the system was increased. No trends were identified in bubble diameter as a function of either power or ionic strength of the aqueous medium; however, gas flow rate increased as both power and ionic strength were increased. The volume distribution of the generated bubbles showed that electroflotation produces bubbles with fairly uniform diameters and narrow ranges. Again, no trends were identified in distribution as functions of either power or ionic strength.

\section{Acknowledgments}

The authors thank Ken Thomas for his assistance with equipment preparation. Partial financial support from the Division of Chemical Sciences, Office of Energy Sciences, US Department of Energy, under contract DE-AC05-960R22464 with Lockheed Martin Energy Research Corp., is gratefully acknowledged.

\section{$\underline{\text { References }}$}

Balmer, L. M. and Foulds, A. W. (1986). Separating Oil from Oil-in-Water Emulsions by Electroflocculation/Electroflotation, Filtration and Separation, Vol. 6, pp. 366-370.

Brandon, N.P. and Kelsall, G.H. (1985). Growth Kinetics of Bubbles Electrogenerated at Microelectrodes, Journal of Applied Electrochemistry, Vol. 15, pp. 475-484.

DE Rijk, S.E, VAN DER Graaf, J.H.J.M., and DEN Blanken (1994). Bubble Size in Flotation Thickening, Water Research, Vol. 28, No. 2, pp. 465-473.

Edzwald, J.K., Walsh, J.P., Kaminski, G.S., and Dunn, H.J. (1992). Flocculation and Air Requirements for Dissolved Air Flotation, Journal of the American Water Works Association, Vol. 3, pp. 92-100.

Glas, J.P. and Westwater, J.W. (1964). Measurement of the Growth of Electrolytic Bubbles, International Journal of Heat and Mass Transfer, Vol. 7, pp. 1427 1443.

Hines, W.W. and Montgomery, D.C. (1990). Probability and Statistics in Engineering and Management Science, Third Edition, John Wiley and Sons, New York, 732 pp. 
Hosny, A.Y. (1992). Separation of Oil from Oil/Water Emulsions Using and Electroflotation Cell with Insoluble Electrodes, Filtration and Separation, Vol. 5, pp. 419-423.

Janssen, L. J. J. and Hoogland, J. G. (1973). The Effect of Electrolytically Evolved Gas Bubbles on the Thickness of the Diffusion Layer - II, Electrochimica Acta, Vol. 18, pp. 543-550.

Ketkar, D.R., Mallikarjunan, R., and Venkatachalam, S. (1991). Electroflotation of Quartz Fines, International Journal of Mineral Processing, Vol. 31, pp. 127. 138.

Landolt, D., Acosta, R., Muller, R.H., and Tobias, C.W. (1970). An Optical Study of Cathodic Hydrogen Evolution in High-Rate Electrolysis, Journal of the Electrochemical Society, Vol. 117, No. 6, pp. 839-845.

Letterman, R.D. (1987). An Overview of Filtration, Journal of the American Water Works Association, Vol. 12, pp. 26-32.

Malley, J.P. and Edzwald, J.K. (1991). Laboratory Comparison of DAF with Conventional Treatment, Journal of the American Water Works Association, Vol. 9, pp. 56-61.

Ramadorai, G. and Hanten, J. P. (1986). Removal of Molybdenum and Heavy Metals from Effluents by Flotation, Minerals and Metallurgical Processing, August, pp. 149-154.

Srinivasan, V. and Subbaiyan, M. (1989). Electroflotation Studies on $\mathrm{Cu}, \mathrm{Ni}, \mathrm{Zn}$, and $\mathrm{Cd}$ with Ammonium Dodecyl Dithiocarbamate, Separation Science and Technology, Vol. 24, No. 1\&2, pp. 145-150.

Verhaart, H.F.A., DE Jonge, R.M., and vAN Stralen, S.J.D. (1980). Growth Rate of a Gas Bubble During Electrolysis in Supersaturated Liquid, International Journal of Heat and Mass Transfer, Vol. 23, pp. 293-299. 